Healthcare Nursing Journal - vol. 4 no. I (2022) Hal 206-2I3

\title{
PENGARUH PIJAT KAKI (FOOT MASSAGE) TERHADAP KUALITAS TIDUR
}

\author{
'Asep Robby, ${ }^{2}$ Teti Agustin, ${ }^{3}$ Hada Hanifan Azka
}

1,2,3 Program Studi Keperawatan, Universitas Bakti Tunas Husada Tasikmalaya

Article Information

Received: Agustus 2021

Revised: November 2021

Available online : Januari 2022

Keywords

kualitas tidur, foot massage, keperawatan

\section{Correspondence}

Phone: (+62) 85217173210

E-mail: aseprobby@stikes-bth.ac.id

\section{ABSTRACT}

Pijat kaki adalah manipulasi jaringan ikat dengan cara memukul, menggosok atau meremas yang berdampak pada peningkatan sirkulasi, memperbaiki tonus otot dan memberikan efek relaksasi. Tujuan dari penelitian ini adalah untuk mengidentifikasi hasil penelitian mengenai pengaruh foot massage terhadap kualitas tidur pasien terutama saat menjalani hospitalisasi. Metode penelitian ini menggunakan studi literatur. Populasi penelitian ini adalah artikel yang diperoleh dari database nasional dan internasional seperti google scolar, science direct, perpustakaan nasional, pubmed. Pengumpulan data kependudukan adalah data primer. Penelusuran artikel dalam rentang 10 tahun yaitu antara tahun 20112021. Hasil yang didapatkan terdapat 18 jurnal dan artikel yang relevan. Berdasarkan hasil penelaahan terhadap artikel tersebut, diperoleh disimpulkan bahwa pijat kaki dapat meningkatkan kualitas tidur pada pasien terutama dengan gangguan tidur. 


\section{PENDAHULUAN}

Kualitas tidur adalah suatu keadaan di mana tidur yang dijalani seorang individu menghasilkan kesegaran dan kebugaran di saat terbangun. Kualitas tidur yang mencakup aspek kuantitatif dari tidur, seperti durasi tidur, latensi tidur serta aspek subjektif, seperti tidur dalam dan istirahat. Penanganan gangguan tidur dapat dilakukan dengan dua cara, yakni farmakologi dan non farmakologi. Farmakologi adalah cara yang digunakan dengan menggunakan obatobatan untuk merangsang penderita untuk dapat tidur. Namun cara ini cenderung berdampak buruk apabila diberikan dalam jangka panjang. Pemberian terapi non farmakologi dapat dilakukan dengan berbagai cara seperti terapi olahraga, hipnosis, reflesi, akupungtur, massage, dll.

Adapun beberapa macam terapi relaksasi yang umum digunakan untuk mengatasi gangguan tidur yaitu seperti relaksasi aroma terapi lavender dengan menggunakan teknik inhalat uap yaitu dengan cara menambahkan 5-6 tetes minyak aroma terapi lavender kedalam mangkok yang berisi air mendidih $\pm 5 c c$ di atas tungku pemanas, kemudian di letakkan didekat pasien yang akan tidur selama 30 menit sehingga aromanya akan dihirup oleh pasien yang mengalami gangguan tidur. Terapi massage punggung dengan cara menggunakan teknik dasar manipulasi effleurage, effleurage merupakan gosokan pada kulit tanpa terjadi gerakan otot bagian dalam dengan gerakan tangan tetap dan tekanan yang diberikan searah dengan aliran darah balik.

Rendam kaki dengan air hangat dapat menimbulkan rasa nyaman, tenang, releks, meringankan rasa sakit, dan melancarkan peredaran darah terutama dapat meningkat kualitas tidur tetapi terapi rendam kaki hanya memiliki waktu tidur efektif sekitar 4 jam. Dan terapi yang terakhir yaitu foot massage dengan menggunakan lotion atau minyak baby oil dilakukan selama 15 detik disetiap bagian kaki, dari mulai telapak kaki, pergelangan kaki, punggung kaki, sampai jarijari kaki.

Foot massage atau pijat kaki dapat memberikan efek relaksasi yang mendalam, mengurangi kecemasan, mengurangi rasa sakit, ketidaknyamanan secara fisik, dan meningkatkan kualitas tidur (Afianti \& Mardhiyah, 2017). Terapi foot massage juga bagus untuk meningkatkan kualitas tidur pasien selain meningkatkan kualitas tidur pasien foot massage juga memberikan kenyamanan untuk pasien selain itu juga foot massage memiliki pertimbangan biaya yang 
rendah, bisa di lakukan dengan mandiri dan prosedur yang mudah sehingga foot massage sangat baik untuk perbaikan kualitas tidur pasien . Foot Massage juga merupakan salah satu terapi komplementer yang aman dan mudah diberikan dan mempunyai efek meningkatkan sirkulasi, mengeluarkan sisa metabolisme,mengurangi rasa sakit,merelaksasikan otot,memberikan rasa nyaman pada pasien dan meningkatkan kualitas tidur.

\section{METODE}

Metode pengumpulan data yaitu melakukan penelusuran menggunakan database penelitian keperawatan kesehatan atau kesehatan, misalnya google scolar, science direct, perpustakaan nasional, pubmed dengan kata kunci : foot massage, kualitas tidur. Waktu publikasi pencarian ini dibatasi dalam kurun waktu 10 tahun terakhir antara tahun 2011-2021 dan dianjurkan mendapatkan artikel minimal 20 artikel,jurnal,book,dan dari website dengan presentase 10 tahun terakhir 30\% dan 5 tahun terakhir $70 \%$

\section{HASIL DAN PEMBAHASAN}

Berdasarkan hasil penelitian Wuisan(2019) dan Ginting (2018), pada pasien yang dirawat di ruang (ICU), diketahui di ruang ICU banyak pasien yang memiliki gangguan tidur penyebab diantaranya lingkungan, kebisingan, pencahayaan, terapi obat dan dari hasil penelitian kepada pasien di ruang ICU menyatakan bahwa foot massage sebagai intervensi yang digunakan pada pasien kritis dikarenakan kaki mudah diakses, mampu merangsang sirkulasi peredaran darah yang dapat membuat suasana hati pasien menjadi nyaman, relaks, dan memiliki pengaruh yang positif sehingga akan mempengaruhi kualitas tidur pasien.

Menurut Naikwadi, dkk. (2020) pengaruh pijat kaki ini memberikan kenyamanan seperti rasa relak pada tubuh, mengurangi persepsi nyeri, memperbaiki kualitas tidur, dengan mempengaruhi sistem lokomotor dan sistem saraf serta sistem kardiovaskular. Selain obat tekanan darah, diet, perubahan gaya hidup, terapi pijat kaki juga dapat meningkatkan kualitas tidur, karena pasien terbanyak adalah tidak mampu mempertahankan tekanan darah yang sehat dengan mudah dan durasi tidur yang normal. Foot massage berefek positif untuk pasien hipertensi dimana setelah menerapkan intervensi ini mereka mendapatkan kesempatan tidur yang baik lebih 
dibandingkan dengan kelompok kontrol yang tidak diberikan intervensi foot massage.

Hasil penelitian Sarısoy dkk (2020) dan Rambod dkk (2019), pada pasien NHL (limfoma non hodgkin) yaitu pasien kanker yang menyerang kelenjar getah bening, pasien mengalami gangguan tidur karena merasakan nyeri neuropatik perifer, nyeri neuropatik berdampak negatif pada pasien status fungsional, kualitas hidup, dan kualitas tidur. Agar pasien bisa memperbaiki kualitas tidur nya diberikan terapi pijat kaki. Didapatkan kualitas tidur kelompok kontrol yang tidak diberikan pijat kaki semakin memburuk, dibandingkan dengan kelompok intervensi yang diberikan terapi pijat kaki. Maka disimpulkan bahwa pijat kaki memiliki efek positif pada kualitas tidur pasien NHL, mengurangi gangguan tidur jangka panjang, dan meningkatkan tingkat normalisasi pola tidur mereka.

Hasil penelitian Samarehfekri dkk (2020) terhadap pasien transplantasi ginjal yang disebabkan penyakit ginjal stadium akhir, pasien yang menjalani operasi transplantasi ginjal merasakan nyeri pasca operasi, kelelahan, dan gangguan tidur. Oleh karena itu, perlu diberikan pijat refleksi kaki, karena pijat refleksi tidak memiliki efek samping yang besar. Kualitas skor tidur pasien pada kelompok yang diberikan pijat refleksi kaki meningkat 1 minggu setelah intervensi dibandingkan dengan kelompok yang tidak diberikan pijat refleksi kaki. Oleh karena itu, pijat refleksi kaki dapat mengurangi rasa sakit dan kelelahan serta meningkatkan kualitas tidur, perawatan sederhana, murah, dan dapat dengan mudah diajarkan kepada perawat di berbagai departemen di pusat perawatan kesehatan

Hasil penelitian Yusman (2020), menyatakan kondisi pada pasien post operasi biasanya timbul ketidaknyamanan fisik pada pasien diantaranya adalah timbul nyeri yang disertai dengan kegelisahan dan mengakibatkan sulit untuk tidur. Salah satu terapi untuk meningkatkan kualitas tidur yaitu dengan pemberian foot massage yang dimulai dari pemijatan kaki dan diakhiri dengan pemijatan telapak kaki sehingga merespon sensor syaraf kaki yang kemudian pijatan pada kaki ini meningkatkan neurotransmiter serotonin dan dopamin yang rangsangannya diteruskan ke hipotalamus dan menghasilkan Corticotropin Releasing Factor (CRF) yang merangsang kelenjar pituary untuk meningkatkan produksi Proopioidmelanocortin (POMC) dan merangsang medula adrenal meningkatkan sekresi endorfin yang mengaktifkan 
parasimpatik sehingga terjadi vasodilatasi pada pembuluh serta memperlancar aliran darah sehingga membantu otot-otot yang tegang menjadi relaks sehingga RAS (Retikuler Aktivating System) terstimulasi untuk melepaskan serotonin dan membantu munculnya rangsangan tidur serta meningkatkan kualitas tidur seseorang.

Hasil penelitian Unal dkk (2016), pada pasien hemodialisis yang mengalami kelelahan karena berbagai alasan yaitu ketidakseimbangan cairan elektrolit, abnormal pengeluaran energi, dan depresi yang menyebabkan pasien mengalami gangguan tidur. Hasil pada penelitian mereka menyatakan bahwa pijat efektif dalam meningkatkan kualitas tidur. Terapi pijat dianggap menghasilkan efek terapeutik dan untuk menurunkan kadar kortisol, norepinefrin,dan epinefrin dengan merangsang sistem saraf, sehingga meningkatkan kualitas tidur pasien. Tetapi pijat pada kaki lebih efektif karena pijat kaki bagian bawah secara sistematik dan ritmik akan mengurangi ketegangan otot, menciptakan suasana relaks yang pada akhirnya dapat memperbaiki kualitas tidur pasien.

Hasil penelitian menurut Mulia, dkk (2019) dan Ujeng dkk (2019). Pada pasien CHF yang mengalami gangguan tidur di malam hari yang disebabkan sesak dan nyeri dada. Penelitian ini menunjukan bahwa gangguan tidur yang dialami pasien jantung dapat meningkatkan hormon adrenalin yang menyebabkan dapat menstimulasi serangan jantung. Begitu juga dengan pasien Congestive Heart Failure (CHF). Tindakan foot massage memiliki pertimbangan biaya rendah, kemungkinan komplikasi yang sedikit dan prosedur yang mudah sehingga foot massage sangat baik untuk perbaikan kualitas tidur. Terdapat perubahan kualitas tidur setelah diberikan foot massage yaitu pasien bisa tertidur lebih cepat yaitu kurang dari 30 menit, sedangkan sebelum diberikan terapi foot massage pasien membutuhkan waktu $>60$ menit untuk tertidur. Ada pun perbedaan hasil penelitian yang dilakukan oleh Ujeng dkk (2019) menunjukan bahwa pengaruh foot massage pada pasien CHF juga mempunyai efek meningkatkan sirkulasi, mengurangi rasa sakit, merelaksasikan dan memberikan rasa nyaman pada pasien.

Hasil penelitian Razi dkk (2017), menyatakan bahwa pijat refleksi kaki meningkatkan kualitas tidur pada wanita dengan diabetes mellitus tipe 2. Pijat refleksi kaki dapat menjadi intervensi yang efektif untuk meningkatkan kualitas tidur pada 
pasien wanita. Berdasarkan hasil penelitian Tussolihah (2018) Coronary Artery Disease (CAD) yaitu penyempitan atau penyumbatan arteri koroner, arteri yang menyalurkan darah ke otot jantung. Bila aliran darah tersumbat, jantung tak mendapat cukup oksigen dan zat nutrisi yang dibutuhkan jantung menjadi berkurang. Akibatnya, timbul rasa nyeri dada yang menganggu pasien untuk tidur. Hasil penelitian ini menyatakan bahwa adanya pengaruh foot massage terhadap pasien Coronary Artery Disease (CAD) karena dapat memperlancar peredaran darah, memberikan rasa rileks pada tubuh, menghilangkan stress, memberikan kebugaran pada tubuh, dan adanya peningkatan dalam kualitas tidur pasien.

Hasil penelitian Malekshahi dkk (2018) menyatakan bahwa adanya pengaruh terapi pijat terhadap kualitas tidur pada pasien penyakit ginjal tahap akhir yang menjalani hemodialisis pijat kaki dilakukan selama 10 menit selama cuci darah, tiga kali seminggu selama 4 minggu berturut-turut menunjukkan bahwa pijat kaki efektif dalam kualitas tidur dapat diimplementasikan dan dilatih sebagai cara yang berguna untuk meningkatkan kualitas tidur pasien di unit hemodialisis

Bedasarkan penelaahan literatur dapat ditemukan bahwa pemberian foot massage saat ini efektif dalam pelayanan keperawatan guna untuk meningkatkan kualitas tidur pada pasien yang mengalami gangguan pada tidur. Foot massage atau pijat kaki dapat memberikan efek relaksasi yang mendalam, mengurangi kecemasan, mengurangi rasa sakit, ketidaknyamanan secara fisik, dan meningkatkan kualitas tidur. Foot massage juga mempunyai beberapa keuntungan diantaranya mempunyai efek meningkatkan sirkulasi, mengeluarkan sisa metabolisme, mengurangi rasa sakit, merelaksasikan otot,memberikan rasa nyaman pada pasien dan meningkatkan kualitas tidur. Dari beberapa penelitian menggambarkan bahwa foot massage adalah salah satu metode yang paling efektif dari terapi komplementer dikarenakan saat pasien diberikan foot massage ada efek relaksasi yang dirasakan pasien sehingga pasien merasa nyaman dan mudah untuk tertidur.

\section{SIMPULAN DAN SARAN}

Bedasarkan hasil penelitian terhadap artikel yang ditemukan dapat disimpulkan bahwa foot massage efektif digunakan dalam asuhan keperawatan sebagai upaya untuk memberikan efek relaksasi yang mendalam, mengurangi kecemasan, mengurangi rasa sakit, ketidaknyamanan secara fisik, dan 
meningkatkan kualitas tidur. Bedasarkan hasil analisis dari beberapa penelitian dapat ditemukan bahwa intervensi foot massage harus diberikan kepada pasien yang mengalami gangguan tidur untuk meningkatkan kualitas tidur pasien. Maka disarankan pelayanan keperawatan dapat menerapkan foot massage ini dalam upaya meningkatkan kualitas pelayanan di institusi pelayanan kesehatan pada pasien yang mengalami gangguan tidur. Karena terapi komplementer ini dapat meningkatkan kualitas tidur pada pasien.

\section{DAFTAR PUSTAKA}

Adinda mulia et al., 2014. pengaruh foot massage terhadap kualitas tidur pada pasien chf (Congestive Heart Failure) di ruang HCU cempaka 2 RSUD dr. Adnaan wd payakumbuh.

Adam Ginting, Dameria., 2020, Pengaruh Foot Massage Terhadap Kualitas Tidur Pasien.

Afianti \& Mardhiyah, 2017. Pengaruh Foot Massage terhadap Kualitas Tidur Pasien di Ruang ICU

Malekshahi, F., Aryamanesh, F., \& Fallahi, S. 2018. The effects of massage therapy on sleep quality of patients with endstage renal disease undergoing hemodialysis. Sleep and Hypnosis, 20, 91-95.

Naikwadi et al., 2020. Effectiveness of Foot Massage on Quality of Sleep among Patients with Hypertension.

Pedram Razi \& Ad, 2018, The Effect of Foot Reflexology Massage on Sleep Quality in Women With Type 2 Diabetes; a Clinical Study

Rambod et al., 2019 The effect of foot reflexology on fatigue, pain, and sleep quality in lymphoma patients: A clinical trial.

Samarehfekri et al., 2020, Effect of Foot Reflexology on Pain, Fatigue, and Quality of Sleep after Kidney Transplantation Surgery: A Parallel Randomized Controlled Trial.

Sarisoy et al., 2020 The effect of foot massage on peripheral neuropathy-related pain and sleep quality in patients with nonhodgkin's lymphoma.

Tussolihah, M., \& Hidayat, F. R., 2018. Analisa Praktek Klinik Keperawatan pada Pasien Coronary Artery Disease (CAD) NON STEMI dengan Intervensi Inovasi Terapi Pijat Kaki terhadap Kualitas Tidur di Ruang Intensive Cardiac Care Unit (ICCU) RSUD Abdul Wahab Sjahranie Samarinda Tahun 2018. 
Ujeng, U., \& Ningrum, N. 2020, Aktivitas Terapi Foot Massage Dan Hand Massage Terhadap Kualitas Tidur Pada Pasien Chf Di Ruang Icu Rsud 45 Kuningan Tahun 2019. Journal of Nursing Practice and Education, 1(1).

Unal, K. S., \& Akpinar, R. B., 2016. The effect of foot reflexology and back massage on hemodialysis patients' fatigue and sleepquality. Complementary therapies in clinical practice, 24, 139144 .

Wuisan, Y. S. 2019. Pengaruh foot massage terhadap kualitas tidur pada pasien di ruangan intensif RSUD dr H. MM Dunda Limbo 